\title{
Diarrhea Is Associated with Increased Severity of Disease in COVID-19: Systemic Review and Metaanalysis
}

\author{
Subash Ghimire ${ }^{1}$ (D) Sachit Sharma ${ }^{2} \cdot$ Achint Patel $^{3} \cdot$ Rasmita Budhathoki $^{4} \cdot$ Raja Chakinala $^{1} \cdot$ Hafiz Khan $^{1}$. \\ Matthew Lincoln ${ }^{1} \cdot$ Michael Georgeston ${ }^{1}$
}

Accepted: 19 November 2020 / Published online: 6 January 2021

(C) Springer Nature Switzerland AG 2021

\begin{abstract}
COVID-19 has become a pandemic since its emergence in Wuhan, China. The disease process was initially defined by presence of respiratory symptoms; however, it is now well studied and shown in evidence that this is a multisystem process. Involvement of gastrointestinal (GI) system has been identified, and GI symptoms can be the only presenting symptoms in some patients. Hence, it is important to identify and understand the GI symptoms associated with COVID-19 for appropriate care of patient. We conducted a systematic review and metaanalysis to identify the GI symptoms of COVID-19 and identify association of diarrhea with severity of COVID-19. We performed extensive search of Medline and Embase from December 2019 to May 2020 to identify articles reporting GI symptoms in COVID-19 patients. The primary outcome was prevalence of GI symptoms in COVID-19 patients, and secondary outcome was the association of diarrhea with disease severity. A total of 38 studies with 8407 patients were included. Of the total patients, $15.47 \%$ patients had at least one GI symptom. The pooled prevalence of nausea/vomiting was $7.53 \%$ and diarrhea was $11.52 \%$. On metaanalysis, patients with diarrhea as one of the presenting symptoms were more likely to have severe disease (OR 1.63, 95\% CI: 1.11-3.38, $p=0.01$ ). Our systematic review and metaanalysis demonstrated that GI symptoms are common in COVID-19. Presence of diarrhea as a presenting symptom is associated with increased disease severity and likely worse prognosis. Early recognition of patients is needed for prompt management of this atrisk population.
\end{abstract}

Keywords COVID-19 $\cdot$ GI $\cdot$ Nausea $\cdot$ Vomiting $\cdot$ Diarrhea $\cdot$ Metaanalysis

\section{Introduction}

Beginning of the year 2020 was marked by a major public health outbreak due to COVID-19 caused by a novel corona virus (SARS-CoV-2), initially reported in Wuhan, China [1, 2]. The severity of illness in COVID-19 usually guides management strategies and has prognostic implications [3]. Severe illness is characterized by severe interstitial pneumonia, acute

This article is part of the Topical Collection on Covid-19

Subash Ghimire

drsubash01@gmail.com

Guthrie Robert Packer Hospital, 1 Guthrie Square, Sayre, PA, USA

2 University of Toledo Medical Center, Toledo, OH, USA

3 Rochester Regional Health, Rochester, NY, USA

4 Jackson Memorial Hospital, University of Miami, Coral Gables, FL, USA respiratory distress syndrome (ARDS), and ultimately multiorgan failure, which results in considerable mortality $[4,5]$. Patients with severe illness are more likely to need prolonged hospitalization, mechanical ventilation, and intensive care unit (ICU) stay [6]. The overall mortality rate is estimated to be about $1-4 \%$ in hospitalized patients, while studies have reported mortality rates up to $32 \%$ in patients with severe disease $[7,8]$.

Gastrointestinal (GI) symptoms are being increasingly reported as common symptoms in COVID-19 patients [9-12]. Gastrointestinal manifestations include loss of appetite, nausea, vomiting, diarrhea, abdominal pain, and deranged liver function tests $[13,14]$. In addition to droplet transmission, fecal viral shedding and subsequent fecal-oral transmission have been identified as another potential route of transmission of the virus [15-17]. Understanding the pattern of GI manifestation in COVID-19 patients may have significant implication in early diagnosis, triaging, and management of patients. Some of the earlier reviews looking at the association of GI symptoms in COVID-19 have been limited to studies in China 
only, with only a few exploring global cases [17]. A trend towards increased disease severity in patients with GI symptoms has been shown in studies $[11,12]$. Therefore, we conducted this systematic review to include studies reported in both China and outside China (USA, Germany, Mexico, Japan, the Netherlands, and Singapore) to provide a more comprehensive and generalizable understanding of the GI manifestations, and its association with severity in COVID19 patients.

\section{Methods}

\section{Data Sources and Searches}

Two authors (SG and SS) independently searched Medical Literature Analysis and Retrieval System Online (MEDLINE) and EMBASE database from December 2019 to May 2020 using search terms as follows: "COVID-19" OR "SARS-CoV-2" OR “coronavirus 2019” OR "2019nCoV" AND "Clinical features" OR "clinical manifestations" OR "nausea" OR "loss of appetite" OR "nausea" OR "vomiting" OR "abdominal pain" OR "diarrhea". Duplicate articles/ abstracts were manually removed by the investigators and through Mendeley 1.19.4 (Amsterdam, Netherlands). We adhered to the Preferred Reporting Items for Systematic Reviews and Meta-Analyses (PRISMA) guidelines for this systematic review.

\section{Study Selection}

Our initial search yielded 380 articles and after careful screening, 38 articles were included for the purpose of study. COVID-19 infection was confirmed by RT-PCR method in all studies. Single case reports and case series were excluded in this study. Additional records which were not in English language were excluded. The study selection process is illustrated in Supplementary File 1.

\section{Quality Assessment and Data Extraction}

Independent data extraction was carried out by 2 authors (SG and SS) using Microsoft Excel spreadsheets incorporating sample size, mean/ median age, and GI manifestations (nausea, vomiting, loss of appetite, abdominal pain, diarrhea and deranged liver function). Severe COVID-19 infection was defined as: new onset hypoxia or respiratory rate $>30$ breaths/ min or $\mathrm{PaO} 2 / \mathrm{FiO} 2<250$ or requiring ICU admission for mechanical ventilation and/or vasopressor support or death, and the data was collected from the reporting in the study. Data collected was appraised by RB and AP, and incongruities were resolved by mutual consensus.

\section{Outcome Measures}

The primary outcome of our study was to assess the proportion of GI manifestations in COVID-19 patients in various geographic locations in the world, and to obtain pooled analysis of the same. Secondary outcome was to estimate the association of GI symptoms, especially diarrhea with severe and nonsevere COVID-19 patients.

\section{Statistical Analysis}

Comprehensive Meta-Analysis software (CMA version 2, Englewood, NJ) was used to calculate pooled prevalence and odds ratio $(\mathrm{OR})$ with $95 \%$ confidence interval $(\mathrm{CI})$. We estimated odds ratio (OR) between GI symptom and severity of COVID19 disease with corresponding 95\% CI and quantifying magnitude of the relationship were pooled using a random-effects model. $I^{2}$ was used to evaluate heterogeneity between studies, and $I^{2}$ value to $>75 \%$ was considered as a significant for the presence of heterogeneity. Funnel plot was used to evaluate publication bias. A 2-tailed $p$ value of $<0.05$ was considered statistically significant for all outcomes between the groups.

\section{Results}

We included 38 observational studies with 8407 confirmed cases of COVID-19 patients with detailed outlining of various GI manifestations (nausea, vomiting, loss of appetite, diarrhea, abdominal pain, deranged liver enzymes). Of these 38 studies, 9 studies reported data on manifestation of the above GI symptoms, especially diarrhea as one of the presenting symptoms in patients with severe or nonsevere COVID-19.

Of the total 38 studies, 37 studies reported data on gender of the patients. Distribution of available data based on country, gender, and mean or median age were obtained, as shown in Table 1 .

Pooled data was obtained from studies with at least one GI symptom, which showed prevalence of any GI symptom to be $15.47 \%$ (95\% CI 11.76-20.09, $I^{2}=96.00$ ), as shown in Table 2. Similarly, pooled prevalence of nausea/vomiting, which was reported by 26 studies was $7.53 \%$ (95\% CI $5.27-$ $\left.10.65, I^{2}=95.03\right)$. Diarrhea was reported by 37 studies with pooled prevalence of $11.52 \%$ (95\% CI $8.97-14.68, I^{2}=$ 93.07). Several studies reported data on deranged liver enzymes as shown in Table 2.

Association between GI symptoms and severity of COVID-19: Nine out of the total 38 studies reported data on diarrhea based on severity of COVID-19, including 2192 patients. There were 1751 patients in nonsevere disease group and 441 patients in severe group as shown in Table 3. Patient with severe disease had higher odds of diarrhea as one of the presenting symptoms (OR 1.63, 95\% CI 1.11-2.38, $p=0.01$ ) (Fig. 1 and Fig. 2). 
Table 1 Demographic features of studies

\begin{tabular}{|c|c|c|c|c|c|c|}
\hline Study name & Type of study & Sample size & Country & $\begin{array}{l}\text { Age (Mean/ } \\
\text { Median) }\end{array}$ & Male & Female \\
\hline Guan W [6] & Multicenter & 1099 & China & 47 (median) & 640 & 459 \\
\hline Young B [18] & Multicenter & 18 & Singapore & 47 (median) & 9 & 9 \\
\hline Pan L [9] & Multicenter & 204 & China & 52.9 (mean) & 107 & 97 \\
\hline Han C [19] & Single center & 206 & China & 62.5 (mean) & 91 & 115 \\
\hline Zhang JJ [20] & Single center & 140 & China & 57 (median) & 71 & 69 \\
\hline Jin X [21] & Multicenter & 651 & China & 46.14 (mean) & 331 & 320 \\
\hline Nobel Y [22] & Single center & 278 & USA & N/A & 145 & 133 \\
\hline Zhou Z [23] & Single center & 254 & China & 50 (Median) & 115 & 139 \\
\hline Cheung K [15] & Multicenter & 59 & Hong Kong & 58.5 (Median) & 27 & 32 \\
\hline Luo S [24] & Single center & 1141 & China & 53.8 (mean) & $N / A$ & $N / A$ \\
\hline Wang D [25] & Single Center & 138 & China & 56 (median) & 75 & 63 \\
\hline Huang C [26] & Single Center & 41 & China & 49 (median) & 30 & 11 \\
\hline Wang Z [27] & Single Center & 69 & China & 42 (median) & 32 & 37 \\
\hline Chen N [28] & Single Center & 99 & China & 55.5 (mean) & 67 & 32 \\
\hline Wu J [29] & Multicenter & 80 & China & 46.1 (mean) & 39 & 41 \\
\hline Shi H [30] & Multicenter & 81 & China & 49.5 (mean) & 42 & 39 \\
\hline Yang X [31] & Single Center & 52 & China & 59.7 (mean) & 35 & 17 \\
\hline Mo P [32] & Single Center & 155 & China & 54 (median) & 86 & 69 \\
\hline Zhou F [33] & Multicenter & 191 & China & 56 (median) & 119 & 72 \\
\hline Chang D [34] & Multicenter & 13 & China & 34(median) & 10 & 3 \\
\hline Liu K [35] & Multicenter & 137 & China & 57 (median) & 61 & 76 \\
\hline Cai Q [36] & Single Center & 298 & China & 47(median) & 149 & 149 \\
\hline Fan Z [37] & Single Center & 148 & China & 50.5 (median) & 73 & 75 \\
\hline Xu X-W [38] & Multicenter & 62 & China & 41(median) & 35 & 27 \\
\hline Zhang B [39] & Single Center & 82 & China & 72.5(median) & 54 & 28 \\
\hline Huang Y [40] & Single Center & 36 & China & 69.22 (mean) & 25 & 11 \\
\hline Wei X [41] & Single Center & 20 & China & N/A & 13 & 7 \\
\hline Song F [42] & Single Center & 51 & China & 49 (median) & 25 & 26 \\
\hline Xiao F [43] & Single Center & 73 & China & N/A & 41 & 32 \\
\hline $\begin{array}{l}\text { Cholankeril G } \\
\text { [44] }\end{array}$ & Single Center & 116 & USA & 50 (median) & 62 & 54 \\
\hline Tabata S [45] & Cruise Ship & 104 & Japan & 68 (median) & 54 & 50 \\
\hline $\begin{array}{l}\text { Kluytmans M } \\
\text { [46] }\end{array}$ & Multicenter & 86 & Netherlands & 49 (median) & 15 & 71 \\
\hline $\begin{array}{l}\text { Hajifathalian K } \\
\text { [47] }\end{array}$ & Multicenter & 1059 & USA & 61 (Median) & 611 & 448 \\
\hline Gritti G [48] & Single center & 21 & Italy & 64 (Median) & 18 & 3 \\
\hline Goyal [49] & Multicenter & 393 & USA & 62 (median) & 238 & 155 \\
\hline Siso [50] & Multicenter & 322 & Spain & 56.7 (Mean) & 161 & 161 \\
\hline $\begin{array}{l}\text { Remes-Troche } \\
\text { [51] }\end{array}$ & Single Center & 112 & Mexico & 43.7 (Mean) & 81 & 31 \\
\hline \multirow[t]{2}{*}{ Redd W [52] } & Multicenter & 318 & USA & 63.4 (Mean) & 174 & 144 \\
\hline & & Total $=8407$ & & & & \\
\hline
\end{tabular}

\section{Discussion}

Our study included studies from December 2019 to May 2020 to analyze the GI symptoms and their significance in COVID-19 patients. This study which includes 8407 patients is a comprehensive analysis of GI symptoms (nausea/vomiting, loss of appetite, abdominal pain, and diarrhea) in patients of COVID-19 infection. As shown in Table 2, pooled prevalence of diarrhea as one of the presenting symptoms was $11.52 \%$. Prevalence of diarrhea reported by multiple studies included in our study ranged from 1.25 to $61.32 \%$. 
Table 2 Prevalence of GI symptoms in multiple studies

\begin{tabular}{|c|c|c|c|c|c|c|c|c|}
\hline \multirow{2}{*}{$\begin{array}{l}\text { Study name } \\
\text { Guan W }\end{array}$} & \multirow{2}{*}{$\begin{array}{l}\text { Sample size } \\
1099\end{array}$} & \multicolumn{2}{|c|}{ GI symptom N (\%) } & \multirow{2}{*}{$\begin{array}{l}\text { Loss of appetite } \\
\text { N/A }\end{array}$} & \multirow{2}{*}{$\begin{array}{l}\text { Nausea/ Vomiting } \\
55\end{array}$} & \multirow{2}{*}{$\begin{array}{l}\text { Abdominal pain } \\
\text { N/A }\end{array}$} & \multirow{2}{*}{$\begin{array}{l}\text { Diarrhea } \\
42\end{array}$} & \multirow{2}{*}{$\begin{array}{l}\text { Deranged LFT } \\
168\end{array}$} \\
\hline & & 55 & $5.00 \%$ & & & & & \\
\hline Young B & 18 & 3 & $16.67 \%$ & $\mathrm{~N} / \mathrm{A}$ & N/A & N/A & 3 & N/A \\
\hline Pan L & 204 & 103 & $50.49 \%$ & 81 & 4 & 2 & 35 & N/A \\
\hline Han C & 206 & 117 & $56.80 \%$ & 102 & 24 & 9 & 67 & $\mathrm{~N} / \mathrm{A}$ \\
\hline Zhang JJ & 140 & 55 & $39.29 \%$ & 17 & 31 & 8 & 18 & $\mathrm{~N} / \mathrm{A}$ \\
\hline Jin $X$ & 651 & 74 & $11.37 \%$ & N/A & 21 & N/A & 53 & N/A \\
\hline Nobel Y & 278 & 97 & $34.89 \%$ & N/A & 63 & N/A & 56 & N/A \\
\hline Zhou Z & 254 & 66 & $25.98 \%$ & N/A & 36 & 3 & 46 & N/A \\
\hline Cheung K & 59 & 15 & $25.42 \%$ & N/A & 1 & 7 & 13 & N/A \\
\hline Luo S & 1141 & 183 & $16.04 \%$ & N/A & 134 & 45 & 68 & N/A \\
\hline Wang D & 138 & 55 & $39.86 \%$ & 55 & 14 & 3 & 14 & N/A \\
\hline Huang C & 38 & 1 & $2.63 \%$ & N/A & N/A & N/A & 1 & 15 \\
\hline Wang Z & 69 & 10 & $14.49 \%$ & 7 & 3 & N/A & 10 & 42 \\
\hline Chen N & 99 & 2 & $2.02 \%$ & N/A & 1 & N/A & 2 & 43 \\
\hline $\mathrm{Wu} \mathrm{J}$ & 80 & 3 & $3.75 \%$ & N/A & 1 & N/A & 1 & 6 \\
\hline Shi H & 81 & 4 & $4.94 \%$ & 1 & 4 & N/A & 3 & 43 \\
\hline Yang $\mathrm{X}$ & 52 & 2 & $3.85 \%$ & N/A & 2 & N/A & N/A & N/A \\
\hline Mo & 155 & 7 & $4.52 \%$ & 26 & 3 & 3 & 7 & N/A \\
\hline Zhou F & 191 & 9 & $4.71 \%$ & N/A & 7 & N/A & 9 & 59 \\
\hline Chang D & 13 & 1 & $7.69 \%$ & N/A & N/A & N/A & 1 & N/A \\
\hline Liu K & 137 & 11 & $8.03 \%$ & N/A & N/A & N/A & 11 & N/A \\
\hline Cai Q & 298 & 9 & $3.02 \%$ & N/A & N/A & N/A & 9 & 44 \\
\hline Fan Z & 148 & 6 & $4.05 \%$ & N/A & 3 & N/A & 6 & 75 \\
\hline Xu X-W & 62 & 3 & $4.84 \%$ & N/A & $\mathrm{N} / \mathrm{A}$ & N/A & 3 & 10 \\
\hline Zhang B & 82 & 10 & $12.20 \%$ & N/A & 2 & N/A & 10 & 64 \\
\hline Huang Y & 36 & 3 & $8.33 \%$ & N/A & N/A & N/A & 3 & N/A \\
\hline Wei X & 20 & 3 & $15.00 \%$ & N/A & 2 & N/A & 3 & N/A \\
\hline Song F & 51 & 9 & $17.65 \%$ & 9 & 3 & N/A & 5 & N/A \\
\hline Xiao F & 73 & 26 & $35.62 \%$ & N/A & N/A & N/A & 26 & N/A \\
\hline Cholankeril G & 116 & 37 & $31.90 \%$ & 22 & 12 & 10 & 12 & 26 \\
\hline Tabata S & 104 & 10 & $9.62 \%$ & N/A & N/A & N/A & 10 & 9 \\
\hline Kluytmans M & 86 & 16 & $18.60 \%$ & 16 & N/A & 5 & 16 & N/A \\
\hline Hajifathalian K & 1059 & 259 & $24.46 \%$ & 240 & 259 & 72 & 234 & N/A \\
\hline Gritti G & 21 & 5 & $23.81 \%$ & 2 & N/A & N/A & 5 & N/A \\
\hline Goyal & 393 & 93 & $23.66 \%$ & N/A & 75 & N/A & 93 & 173 \\
\hline Siso & 322 & 74 & $22.98 \%$ & N/A & N/A & N/A & 74 & N/A \\
\hline Remes-Troche & 112 & 23 & $20.54 \%$ & N/A & 8 & 11 & 20 & 20 \\
\hline Redd W & 318 & 195 & $61.32 \%$ & 110 & 133 & 46 & 107 & N/A \\
\hline
\end{tabular}

Pooled data

GI symptom: $15.47 \%$ (95\% CI 11.76-20.09, I2 = 96.00)

Nausea/ vomiting: $7.53 \%$ (95\% CI 5.27-10.65, I2 = 95.03)

Diarrhea: $11.52 \%$ (95\% CI 8.97-14.68, I2=93.07)

There have been varying GI manifestations of previous corona virus outbreaks. Leung et al. [53] in 2003 published data on severe acute respiratory syndrome (SARS) patients with gastrointestinal symptoms and found that $20.3 \%$ of patients had diarrhea on presentation and up to $38.4 \%$ had diarrhea during the course of illness. A study in 2015 had shown about $30 \%$ of patients with Middle East respiratory syndrome (MERS) had diarrhea [54]. 
Table 3 Prevalence of diarrhea in severe and non-severe cases

\begin{tabular}{llllll}
\hline & \multicolumn{2}{l}{ Non severe } & & & Severe \\
\cline { 2 - 3 } \cline { 5 - 6 } \cline { 5 - 6 } & Diarrhea & Total cases & & Diarrhea & Total cases \\
\hline Guan W & 32 & 926 & & 10 & 173 \\
Young B & 3 & 12 & & 0 & 6 \\
Zhang JJ & 9 & 82 & & 9 & 57 \\
Nobel Y & 42 & 207 & & 11 & 44 \\
Wang D & 8 & 102 & & 6 & 36 \\
Huang C & 0 & 13 & & 1 & 25 \\
Wang Z & 8 & 55 & & 2 & 14 \\
Cai Q & 5 & 240 & & 4 & 58 \\
Tabata S & 7 & 114 & 3 & 28 \\
N= & 114 & 1751 & 46 & 441 \\
\hline
\end{tabular}

(OR $1.63,95 \%$ CI $1.11-2.38, \mathrm{p}=0.01)$

A retrospective multicenter study from China by Guan et al. [6] comprising of more than 1000 patients showed diarrhea to be present in $3.8 \%$ of patients. Similarly, retrospective study by Luo et al. [24] showed all GI symptoms and diarrhea at $16 \%$ and $5.9 \%$ respectively. Cheung et al. [15] from Hong Kong have reported GI symptoms in $25 \%$ of patients with COVID-19. Data presented by Nobel et al. [22] from NY, USA, reported GI symptoms and diarrhea in $34.8 \%$ and $20 \%$ of patients respectively. Cholankeril et al. [44] have reported GI symptoms and diarrhea in COVID-19 patients in CA, USA, at $31.9 \%$ and $12 \%$ respectively. There appears to be regional variation in COVID-19 GI symptomatology throughout the world. A large-scale study of 16,749 patients of COVID-19 who were hospitalized in the United Kingdom (UK) reported GI symptoms in $29 \%$ of patients on admission and $4 \%$ of patients presented with GI symptoms only on admission [55].

Our metaanalysis shows that severe COVID-19 infection was significantly more in patients who had diarrhea (OR: 1.6) (Table 3 and Fig. 1). All studies included in our metaanalysis had higher prevalence of diarrhea in severe cases, except study by Young et al. [18] in Singapore. Metaanalysis on GI manifestations of COVID-19 infection done by Cheung et al. [15] has shown pooled prevalence of GI symptoms to be $15.3 \%$ similar to $15.47 \%$ in our study. They also showed stool viral RNA detected in $48.1 \%$ COVID-19 patients, and $70 \%$ samples were positive even after respiratory samples were negative [15].

SARS-COV-2 entry into human cell is facilitated by interaction between spike protein attached to viral envelope and angiotensin-converting enzyme (ACE)-2 in the human cell. This is about 10-20 times stronger than SARS-COV present in 2003. [56] ACE2 receptor is expressed in type II pneumocytes in lungs, upper esophagus and in the enterocytes in ileum and colon. When the virus attaches to enterocytes, this likely alters intestinal permeability, resulting in malabsorption and diarrhea [13].

Xiao et al. [43] examined stool samples of 73 hospitalized patients with SARS-CoV-2 and found viral RNA positive in $53.4 \%$ of patients, and this lasted up to 12 days after onset of
Fig. 1 Forest plot of studies with odds ratio

\begin{tabular}{|c|c|c|c|c|c|}
\hline \multirow[t]{2}{*}{ Study name } & \multicolumn{4}{|c|}{ Statistics for each study } & \multirow[t]{2}{*}{ Odds ratio and $95 \% \mathrm{CI}$} \\
\hline & $\begin{array}{l}\text { Odds } \\
\text { ratio }\end{array}$ & $\begin{array}{l}\text { Lower Upper } \\
\text { limit limit }\end{array}$ & Z-Value p & Value & \\
\hline Guan W & 1.714 & 0.8263 .555 & 1.448 & 0.148 & \\
\hline Young B & 0.209 & 0.0094 .760 & -0.982 & 0.326 & \\
\hline Zhang JJ & 1.521 & 0.5634 .106 & 0.827 & 0.408 & \\
\hline Nobel Y & 1.310 & 0.6112 .805 & 0.694 & 0.488 & \\
\hline Wang D & 2.350 & $0.755 \quad 7.315$ & 1.475 & 0.140 & \\
\hline Huang C & 1.653 & 0.06343 .443 & 0.301 & 0.763 & \\
\hline Wang Z & 0.979 & $0.184 \quad 5.223$ & -0.025 & 0.980 & \\
\hline Cai Q & 3.481 & 0.90513 .398 & 1.814 & 0.070 & \\
\hline \multirow[t]{2}{*}{ Tabata S } & 1.834 & $0.443 \quad 7.595$ & 0.837 & 0.403 & \\
\hline & 1.634 & 1.1192 .385 & 2.544 & 0.011 & \\
\hline
\end{tabular}


Funnel Plot of Standard Error by Log Odds Ratio

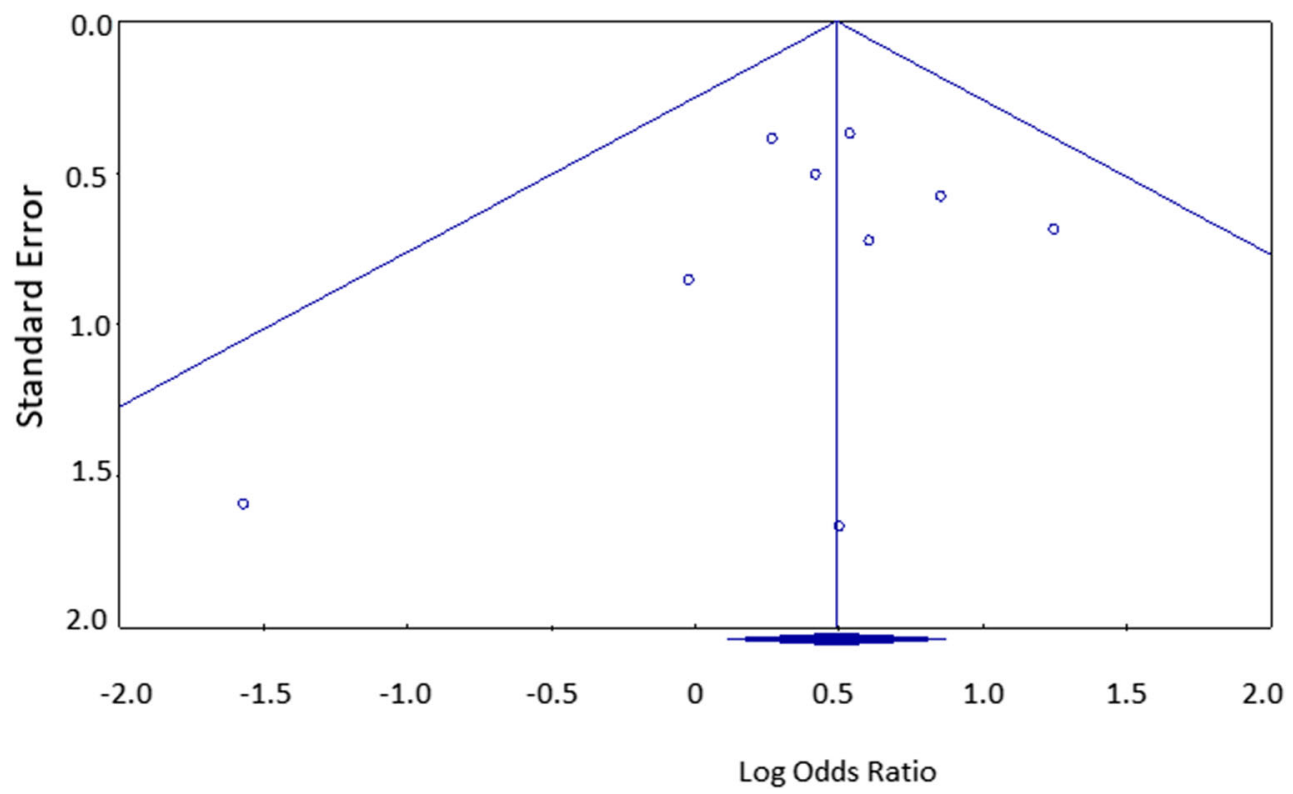

Fig. 2 Funnel plot depicting publication bias

disease. In these patients, they also demonstrated that $23 \%$ had positive stool sample despite having negative respiratory samples, which points towards prolonged viral shedding in GI tract. This raises concern for fecal-oral transmission of the virus [43]. MERS-CoV, during 2015 was detected in stools up to 24 days after diagnosis, and affected up to $15 \%$ of patients [57]. Another study demonstrated that even asymptomatic patients may be shedding infectious virus and at risk for disease transmission [58]. For discontinuation of transmission based precautions, the Center for Disease Control (CDC) currently recommends at least 2 simultaneous specimens collected from the respiratory tract $\geq 24 \mathrm{~h}$ apart after resolution of fever and improvement in respiratory symptoms [59]. Findings by Xiao et al. [43] suggest that feco-oral transmission might happen even after nasopharyngeal viral shedding is cleared. They also found that ACE2 receptor in the GI tract was present in cilia of glandular epithelial cells, which is the site of attachment for the virus [43]. In another study, Xiao et al. [60] examined the fecal specimen from COVID-19 patients and were able to isolate infectious virus in the feces, raising the possibility of fecal-oral transmission. The results in our study could indirectly point to the fact that patients who have diarrhea likely harbor increased viral load, which can potentially lead to an increased systemic response to the virus and associated respiratory complications from it. Our study has significance in COVID-19 patients who need endoscopic procedures. Despite respiratory specimens being negative, isolation precautions may need to be continued until fecal specimens are negative. Outpatient nonemergent GI procedures need to be performed with precautions in COVID-19 patients who have recovered from the disease. Feco-oral contamination needs to be avoided with significant level of precaution. No specific guidelines on this have been provided by American College of Gastroenterology so far [61]. Besides diarrhea, Guan et al. [6] have reported that prevalence of nausea, vomiting, and deranged liver profile was more in patients with severe disease. Similar finding for nausea/vomiting was reported by Wang et al. [25] as well.

Several investigational treatments for COVID-19 including remdesivir, hydroxychloroquine, interleukin-6 (IL-6) inhibitors, convalescent plasma and immune globulins, and lopinavir/ritonavir are currently being studied in clinical trials (CORIMUNO-TOCI, NCT04302766, NCT04347681, NCT04340544, NCT04307693). [62] With a goal of resolution of respiratory compromise, effect of these potential therapies on GI manifestation of COVID-19, including fecal viral clearance is necessary to reduce the risk of potential feco-oral transmission.

There are several limitations of this study. All the included studies were retrospective studies. GI symptoms may be underreported in studies, which unintentionally can result in lower pooled prevalence of gastrointestinal symptoms.

There was also significant heterogeneity in the prevalence of GI symptoms. There are numerous strengths of our study as well. Till date, most of the studies, including research articles on recommendations from professional societies in gastroenterology, are driven by data available from mainland China [10]. To our knowledge, our study is the most inclusive of all the studies, summating studies reported from all over the world. This decreases the geographic bias of the paper and improves external validity. It allows for meticulous estimation of the burden of gastrointestinal impact of COVID-19. Our 
subgroup analysis highlights the importance of careful consideration of a patient's gastrointestinal signs and symptoms, which can get undermined while focusing solely on respiratory system involvement.

Supplementary Information The online version contains supplementary material available at https://doi.org/10.1007/s42399-020-00662-w.

Authors' Contributions SG, RB, and SS wrote manuscript. AP and RC performed statistics. HK and ML reviewed articles and edited manuscript. MG edited manuscript.

Data Availability Yes

\section{Compliance with Ethical Standards}

Conflict of Interest None.

A statement specifying whether or not the authors have a conflict of interest should be included. Further details on Disclosure of Potential Conflicts of Interest can be found below.

Ethics Approval (Include Appropriate Approvals or Waivers) Waived.

Consent to Participate (Include Appropriate Statements) Not applicable.

Consent for Publication (Include Appropriate Statements) Not applicable.

Code Availability (Software Application or Custom Code) Yes.

\section{References}

1. Morens DM, Daszak P, Taubenberger JK. Escaping Pandora's box - another novel coronavirus. N Engl J Med. 2020;382:1293-5.

2. Del Rio C, Malani PN. COVID-19 - new insights on a rapidly changing epidemic. JAMA. 2020;323:1339-40.

3. Gandhi RT, Lynch JB, del Rio C. Mild or moderate Covid-19. N Engl J Med. 2020;383:1757-66. https://doi.org/10.1056/ nejmcp2009249.

4. Pascarella G, Strumia A, Piliego C, Bruno F, Del Buono R, Costa F, et al. COVID-19 diagnosis and management: a comprehensive review. J Intern Med. 2020;288:192-206. https://doi.org/10.1111/ joim.13091.

5. Lake MA. What we know so far: COVID-19 current clinical knowledge and research. Clin Med. 2020;20:124-7.

6. Guan WJ, Ni ZY, Hu YYHY, Liang WH, Ou CQ, He JX, et al. Clinical characteristics of coronavirus disease 2019 in China. N Engl J Med. 2020;382:1708-20.

7. Mei H, Dong X, Wang Y, Tang L, Hu Y. Managing patients with cancer during the COVID-19 pandemic: frontline experience from Wuhan. Lancet Oncol. 2020;21:634-6.

8. Fauci AS, Lane HC, Redfield RR. Covid-19 - navigating the uncharted. N Engl J Med. 2020;382:1268-9.

9. Pan L, Mu M, Yang P, Sun Y, Wang R, Yan J, et al. Clinical characteristics of COVID-19 patients with digestive symptoms in Hubei, China. Am J Gastroenterol. 2020;115:766-73.

10. Sultan S, Altayar O, Siddique SM, Davitkov P, Feuerstein JD, Lim $\mathrm{JK}$, et al. AGA Institute rapid review of the GI and liver manifestations of COVID-19, meta-analysis of international data, and recommendations for the consultative management of patients with COVID-19. Gastroenterology. 2020;159:320-334.e27. https://doi. org/10.1053/j.gastro.2020.05.001.

11. An P, Chen H, Ren H, Su J, Ji M, Kang J, et al. Gastrointestinal symptoms onset in COVID-19 patients in Wuhan, China. Dig Dis Sci. 2020. https://doi.org/10.1007/s10620-020-06693-6.

12. Ye L, Yang Z, Liu J, Liao L, Wang F. Digestive system manifestations and clinical significance of coronavirus disease 2019 (COVID-19): a systematic literature review. J Gastroenterol Hepatol. 2020. https://doi.org/10.1111/jgh.15323.

13. Gu J, Han B, Wang J. COVID-19: gastrointestinal manifestations and potential fecal-Oral transmission. Gastroenterology. 2020;158:1518-9.

14. Lee IC, Huo TI, Huang YH. Gastrointestinal and liver manifestations in patients with COVID-19. J Chin Med Assoc. 2020;83:5213. https://doi.org/10.1097/JCMA.0000000000000319.

15. Cheung KS, Hung IF, Chan PP, et al. Gastrointestinal manifestations of SARS-CoV-2 infection and virus load in fecal samples from the Hong Kong cohort and systematic review and meta-analysis. Gastroenterology. 2020;S0016-5085:30448-0.

16. Xu Y, Li X, Zhu B, Liang H, Fang C, Gong Y, et al. Characteristics of pediatric SARS-CoV-2 infection and potential evidence for persistent fecal viral shedding. Nat Med. 2020;26:502-5.

17. Sonkar C, Kashyap D, Varshney N, Baral B, Jha HC. Impact of gastrointestinal symptoms in COVID-19: a molecular approach. SN Compr Clin Med. 2020. https://doi.org/10.1007/s42399-020-00619-z.

18. Young BE, Ong SWX, Kalimuddin S, Low JG, Tan SY, Loh J, et al. Epidemiologic features and clinical course of patients infected with SARS-CoV-2 in Singapore. JAMA. 2020;323:1488-94.

19. Han C, Duan C, Zhang S, Spiegel B, Shi H, Wang W, et al. Digestive symptoms in COVID-19 patients with mild disease severity. Am J Gastroenterol. 2020;115:916-23.

20. Zhang JJ, Dong X, Cao YY, Yuan YD, Yang YB, Yan YQ, Akdis CA, Gao YD. Clinical characteristics of 140 patients infected with SARSCoV-2 in Wuhan. China Allergy. 2020;75(7):1730-41.

21. Jin X, Lian JS, Hu JH, Gao J, Zheng L, Zhang YM, et al. Epidemiological, clinical and virological characteristics of 74 cases of coronavirus-infected disease 2019 (COVID-19) with gastrointestinal symptoms. Gut. 2020;69(6):1002-9.

22. Nobel YR, Phipps M, Zucker J, Lebwohl B, Wang TC, Sobieszczyk ME, et al. Gastrointestinal symptoms and COVID19: case-control study from the United States. Gastroenterology. 2020;S0016-5085:30490-X.

23. Zhou Z, Zhao N, Shu Y, Han S, Chen B, Shu X. Effect of gastrointestinal symptoms on patients infected with COVID-19. Gastroenterology. 2020;S0016-5085:30362-0.

24. Luo S, Zhang X, Xu H. Don't Overlook Digestive Symptoms in Patients With 2019 Novel Coronavirus Disease (COVID-19). Clin Gastroenterol Hepatol. 2020;18(7):1636-7.

25. Wang $\mathrm{D}, \mathrm{Hu} \mathrm{B}, \mathrm{Hu} \mathrm{C}, \mathrm{Zhu} \mathrm{F}$, Liu X, Zhang J, et al. Clinical characteristics of 138 hospitalized patients with 2019 novel coronavirus-infected pneumonia in Wuhan, China. JAMA. 2020;323:1061-9.

26. Huang C, Wang Y, Li X, Ren L, Zhao J, Hu Y, et al. Clinical features of patients infected with 2019 novel coronavirus in Wuhan, China. Lancet. 2020;395:497-506.

27. Wang Z, Yang B, Li Q, Wen L, Zhang R. Clinical Features of 69 Cases With Coronavirus Disease 2019 in Wuhan. China Clin Infect Dis. 2020;71(15):769-77.

28. Chen N, Zhou M, Dong X, Qu J, Gong F, Han Y, et al. Epidemiological and clinical characteristics of 99 cases of 2019 novel coronavirus pneumonia in Wuhan, China: a descriptive study. Lancet. 2020;395:507-13.

29. Wu J, Liu J, Zhao X, Liu C, Wang W, Wang D, Xu W, Zhang C, Yu J, Jiang B, Cao H, Li L. Clinical Characteristics of Imported Cases of Coronavirus Disease 2019 (COVID-19) in Jiangsu 
Province: A Multicenter Descriptive Study. Clin Infect Dis. 2020;71(15):706-12.

30. Shi H, Han X, Jiang N, Cao Y, Alwalid O, Gu J, et al. Radiological findings from 81 patients with COVID-19 pneumonia in Wuhan, China: a descriptive study. Lancet Infect Dis. 2020;20:425-34.

31. Yang X, Yu Y, Xu J, Shu H, Xia J', Liu H, et al. Clinical course and outcomes of critically ill patients with SARS-CoV-2 pneumonia in Wuhan, China: a single-centered, retrospective, observational study. Lancet Respir Med. 2020;8:475-81.

32. Mo P, Xing Y, Xiao Y, Deng L, Zhao Q, Wang H, et al. Clinical characteristics of refractory COVID-19 pneumonia in Wuhan, China. Clin Infect Dis. 2020. https://doi.org/10.1093/cid/ciaa270.

33. Zhou F, Yu T, Du R, et al. Clinical course and risk factors for mortality of adult inpatients with COVID-19 in Wuhan, China: a retrospective cohort study. Lancet. 2020;395:1054-62.

34. Chang D, Lin M, Wei L, Xie L, Zhu G, Dela Cruz CS, et al. Epidemiologic and clinical characteristics of novel coronavirus infections involving 13 patients outside Wuhan, China. JAMA. 2020;323:1092-3.

35. Kui L, Fang YY, Deng Y, et al. Clinical characteristics of novel coronavirus cases in tertiary hospitals in Hubei Province. Chin Med J. 2020;133:1025-31.

36. Cai Q, Huang D, Ou P, et al. COVID-19 in a designated infectious diseases hospital outside Hubei Province, China. Allergy. 2020;n/a:1-11.

37. Fan Z, Chen L, Li J, Cheng X, Yang J, Tian C, Zhang Y, Huang S, Liu Z, Cheng J. Clinical Features of COVID-19-Related Liver Functional Abnormality. Clin Gastroenterol Hepatol. 2020;18(7): $1561-6$.

38. $\mathrm{Xu} X \mathrm{XW}, \mathrm{Wu} \mathrm{XX}$, Jiang $\mathrm{XG}$, et al. Clinical findings in a group of patients infected with the 2019 novel coronavirus (SARS-Cov-2) outside of Wuhan, China: retrospective case series. BMJ. 2020;368:1-7.

39. Zhang B, Zhou X, Qiu Y, Song Y, Feng F, Feng J, Song Q, Jia Q, Wang J. Clinical characteristics of 82 cases of death from COVID19. PLoS One. 2020;15(7):e0235458.

40. Huang Y, Yang R, Xu Y, Gong P. Clinical characteristics of 36 non-survivors with COVID-19 in Wuhan, China. medRxiv; 2020. https://doi.org/10.1101/2020.02.27.20029009.

41. Xia W, Shao J, Guo Y, et al. Clinical and CT features in pediatric patients with COVID-19 infection: different points from adults. Pediatr Pulmonol. 2020;55:1169-74.

42. Song F, Shi N, Shan F, Zhang Z, Shen J, Lu H, et al. Emerging 2019 novel coronavirus (2019-NCoV) pneumonia. Radiology. 2020;295:210-7.

43. Xiao F, Tang M, Zheng X, Liu Y, Li X, Shan H. Evidence for gastrointestinal infection of SARS-CoV-2. Gastroenterology. 2020;158:1831-1833.e3.

44. Cholankeril G, Podboy A, Aivaliotis VI, Tarlow B, Pham EA, Spencer $\mathrm{S}$, et al. High prevalence of concurrent gastrointestinal manifestations in patients with SARS-CoV-2: early experience from California. Gastroenterology. 2020;S0016-5085:30471-6.

45. Tabata S, Imai K, Kawano S, et al. The clinical characteristics of COVID-19: a retrospective analysis of 104 patients from the outbreak on board the Diamond Princess cruise ship in Japan. medRxiv; 2020. https://doi.org/10.1101/2020.03.18.20038125.

46. Kluytmans-van den Bergh MF, Buiting AG, Pas SD, et al. SARSCoV-2 infection in 86 healthcare workers in two Dutch hospitals in March 2020. medRxiv; 2020. https://doi.org/10.1101/2020.03.23. 20041913

47. Hajifathalian K, Krisko T, Mehta A, et al. Gastrointestinal and hepatic manifestations of 2019 novel coronavirus disease in a large cohort of infected patients from New York: clinical implications. Gastroenterology. 2020;S0016-5085:30602-8.

48. Gritti G, Raimondi F, Ripamonti D, et al. Use of siltuximab in patients with COVID-19 pneumonia requiring ventilatory support. medRxiv; 2020. https://doi.org/10.1101/2020.04.01.20048561.

49. Goyal P, Choi JJ, Pinheiro LC, Schenck EJ, Chen R, Jabri A, et al. Clinical characteristics of Covid-19 in New York City. N Engl J Med. 2020;382:2372-4. https://doi.org/10.1056/NEJMc2010419.

50. Sisó-Almirall A, Kostov B, Mas-Heredia M, Vilanova-Rotllan S, Sequeira-Aymar E, Sans-Corrales M, et al. (2020). Clinical Features of Covid-19 in Barcelona City. Retrieved from https:// deepblue.lib.umich.edu/handle/2027.42/155329. Accessed 28 Sep 2020.

51. Remes-Troche JM, Ramos-de-la-Medina A, Manríquez-Reyes M, Martínez-Pérez-Maldonado L, Lara EL, Solís-González MA. Initial gastrointestinal manifestations in patients with SARS-CoV-2 in 112 patients from Veracruz (southeastern Mexico). Gastroenterology. 2020;:S0016-5085:34708-9.

52. Redd WD, Zhou JC, Hathorn KE, McCarty TR, Bazarbashi AN, Thompson CC, et al. Prevalence and characteristics of gastrointestinal symptoms in patients with SARS-CoV-2 infection in the United States: a multicenter cohort study. Gastroenterology. 2020;S0016-5085:30564-3.

53. Leung WK, To KF, Chan PKS, Chan HLY, Wu AKL, Lee N, et al. Enteric involvement of severe acute respiratory syndrome - associated coronavirus infection. Gastroenterology. 2003;125:1011-7.

54. Chan JFW, Lau SKP, To KKW, Cheng VCC, Woo PCY, Yuen KY. Middle East respiratory syndrome coronavirus: another zoonotic Betacoronavirus causing SARS-like disease. Clin Microbiol Rev. 2015;28:465 LP-522.

55. Docherty A, Harrison E, Green C, Hardwick H, Pius R, Norman L, et al. Features of 16,749 hospitalised UK patients with COVID-19 using the ISARIC WHO clinical characterisation protocol. Preprint at medRxiv; 2020. https://doi.org/10.1101/2020.04.23.20076042.

56. Wan Y, Shang J, Graham R, Baric RS, Li F. Receptor recognition by the novel coronavirus from Wuhan: an analysis based on decade-long structural studies of SARS coronavirus. J Virol. 2020;94:e0127-0.

57. Zhou J, Li C, Zhao G, et al. Human intestinal tract serves as an alternative infection route for Middle East respiratory syndrome coronavirus. Sci Adv. 2017;3:eaao4966.

58. Hindson J. COVID-19: faecal-oral transmission? Nat Rev Gastroenterol Hepatol. 2020;17:259.

59. Center for Disease Control and Prevention. Discontinuation of transmission-based precautions and disposition of patients with COVID-19 in healthcare settings (interim guidance) [Updated May 2, 2020]. https://www.cdc.gov/coronavirus/2019-ncov/hcp/ disposition-hospitalizedpatients.html. Accessed 5 June 2020.

60. Xiao F, Sun J, Xu Y, Li F, Huang X, Li H, et al. Infectious SARSCoV-2 in feces of patient with severe COVID-19. Emerg Infect Dis. 2020;26:1920-2. https://doi.org/10.3201/eid2608.200681.

61. American Journal of Gasstroenterology. COVID-19 and GI. 2020. Retrieved from https://gi.org/media/covid-19-and-gi/. Accessed 5 June 2020.

62. National Institute of Health. What's new. 2020. Retrieved from https:/www.covid19treatmentguidelines.nih.gov/whats-new/. Accessed 28 Nov 2020.

Publisher's Note Springer Nature remains neutral with regard to jurisdictional claims in published maps and institutional affiliations. 